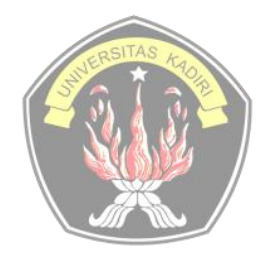

Tersedia online di

http://ojs.unik-kediri.ac.id/index.php/ekonika

do:

http://dx.doi.org/10.30737/ekonika.v5i2.848

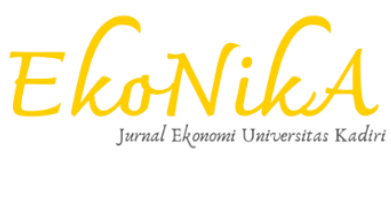

\title{
Analisis Prediksi Kebangkrutan Terhadap Harga Saham Dengan Model Zmijewski Dan Springate (Studi Empiris Pada Perusahaan Sub Sektor Pertambangan Minyak Dan Gas Bumi Dan Batubara Yang Tercatat Di Bei Tahun 2016-2018)
}

${ }^{1}$ Novi Darmayanti, ${ }^{2}$ Isnaini Anniswati Rosyida, ${ }^{3}$ Eti Nasrotul Fauziyah

${ }^{1,2}$ Universitas Islam Darul Ulum Lamongan

${ }^{3}$ Mahasiswa Universitas Islam Darul Ulum Lamongan

email: ${ }^{1}$ novismile_ub@yahoo.com, ${ }^{2}$ isnaini@unisda.ac.id

\section{Artikel History:}

Artikel masuk : 10-08-2020

Artikel revisi : 27-08-2020

Artikel diterima : 02-09-2020

Keywords:

Bankruptcy prediction;

Zmijewski capital;

Springate capital;

stock price

\section{ABSTRAK}

Industri pertambangan memiliki empat macam risiko, yaitu penemuan ketidakpastian sumberdaya berupa minyak dan gas bumi, risiko teknologi yang terkait dengan ketidakpastian biaya, risiko pasar yang terkait dengan pergeseran harga, dan risiko kebijakan pemerintah yang terkait dengan harga domestik serta perubahan pajak. Tujuan penelitian ini adalah untuk mengetahui seberapa besar pengaruh prediksi kebangkrutan menggunakan model Zmijewski (X-Score) dan Springate (S-Score) terhadap harga saham pada perusahaan. Sampel dalam penelitian ini adalah perusahaan sub sektor pertambangan minyak dan gas bumi dan batubara yang tercatat di bei tahun 2016-2018 dengan jumlah 15 perusahaan dengan menggunakan purposive sampling. Metode analisis yang digunakan adalah analisis regresi linier berganda dengan menggunakan programSPSS versi 22. Hasil penelitian menunjukkan Modal Zmijewski tidak signifikan terhadap Harga Saham, Modal Springate berpengaruh positif dan signifikan terhadap Harga Saham, dan Modal Zmijewski dan Modal Springate secara simultan berpengaruh signifikan terhadap Harga Saham.

\section{ABSTRACT}

The mining industry has four types of risks, namely the discovery of uncertainties in the form of oil and gas resources, technological risks associated with uncertainty in costs, market risks associated with price shifts, and the risk of government policies related to domestic prices and tax changes. The purpose of this study was to determine how much influence the prediction of bankruptcy using the Zmijewski (X-Score) and Springate (S-Score) models on the stock price of the company. The sample in this study were oil and gas mining and coal sub-sector companies which were listed on the year 2016-2018 with a total of 15 companies using purposive sampling. The analytical method used is multiple linear regression analysis using SPSS version 22. The results show that Zmijewski Capital is not significant to Stock Prices, Springate Capital has a 
positive and significant effect on Stock Prices, and Zmijewski Capital and Springate Capital simultaneously have a significant effect on Stock Prices.

\section{PENDAHULUAN}

\section{Latar Belakang Masalah}

Industri pertambangan memiliki empat macam risiko, yaitu penemuan ketidakpastian sumberdaya berupa minyak dan gas bumi, risiko teknologi yang terkait dengan ketidakpastian biaya, risiko pasar yang terkait dengan pergeseran harga, dan risiko kebijakan pemerintah yang terkait dengan harga domestik serta perubahan pajak. (M. P. Sari \& Yunita, 2019).

Pada tahun 2016, yaitu tahun penuh rintangan bagi perusahaan minyak dan gas bumi. Harga minyak mencapai titik rendah selama 10 tahun terakhir yaitu mencapai di AS \$29,30 per barrel. Akibat dari penurunan harga minyak yang dapat memengaruhi peralatan permin yakan dalam kurun waktu yang cukup lama (Hikmah, 2018).

Di awal tahun 2012 hingga tahun 2016 harga batubara terus menurun. Ditjen Minerba Kementerian ESDM mencatat harga batu bara acuan (HBA) penjualan langsung (spot) Januari 2016 turun ke USD 53,20 per ton dibandingkan bulan sebelumnya sebesar USD 53,51 per ton.

Turunnya harga batubara ini menyebabkan banyak perusahaan pertambangan batu bara tidak lagi beroperasi, dan ekspor batu bara Indonesia menjadi menurun. Sehingga membuat perusahaan-perusahaan batubara menderita kerugian, ditambah dengan adanya kebijakan baru pemerintah tentang pembatasan ekspor batubara dengan mengeluarkan Peraturan Menteri Perdagangan Republik Indonesia Nomor 39/M-DAG/7/2014 tentang ketentuan ekspor batubara dan produk batubara pasal 2 yang berisi tentang pembatasan eksport batubara yang diberlakukan mulai bulan Oktober 2014, tentunya akan berpengaruh terhadap turunnya nilai ekspor batubara setelah diberlakukannya Permendag tersebut (Marliawati et al, 2016).

Oleh karena itu, apabila perusahaan tidak dapat bertahan dalam keadaan tersebut maka perusahaan khususnya sektor pertambangan minyak dan gas bumi dan batubara kemungkinan akan mengalami kerugian yang akan mempengaruhi kondisi keuangan perusahaan, pada akhirnya perusahaan akan mengalami financial distress atau ancaman kebangkrutan. Kebangkrutan merupakan keadaan dimana perusahaan mengalami ketidakcukupan modal untuk menjalankan usahanya (Adriawan \& Salen, 2016). 
Oleh karena itu sebelum perusahaan diprediksi bangkrut, langkah yang tepat yaitu melakukan pencegahan atau antisipasi dini agar perusahaan dapat mengetahui kelemahankelemahan untuk diperbaiki secepatnya. Untuk memprediksi kebangkrutan ada beberapa model yang dapat digunakan, diantaranya adalah model Zmijewski (X-Score) dan Springate (SScore).

Beberapa peneliti terdahulu telah membuktikan dengan analisis diskriminan dalam memprediksi kebangkrutan perusahaan. Seperti penelitian yang dilakukan (Wibowo, 2015) menunjukkan terdapat hubungan antara model kebangkrutan zmijewski terhadap harga saham. Selanjutnya (Effendi et al., 2016) dalam penelitiannya menyatakan model Spingate berpengaruh signifikan terhadap harga saham.

\section{Rumusan Masalah}

Berdasarkan latar belakang yang telah dikemukakan diatas, maka permasalahan yang terdapat dalam penelitian ini adalah sebagai berikut:

1. Bagaimana pengaruh prediksi kebangkrutan menggunakan model Zmijewski (X-Score) terhadap harga saham pada perusahaan?

2. Bagaimana pengaruh prediksi kebangkrutan menggunakan model Springate (S-Score) terhadap harga saham pada perusahaan?

Bagaimana pengaruh prediksi kebangkrutan menggunakan model Zmijewski (X-Score) dan Springate (S-Score) terhadap harga saham pada perusahaan?

\section{TINJAUAN PUSTAKA}

\section{Kerangka Teoritis}

Dalam Signaling Theory memberitahukan bahwa perusahaan yang mempunyai kinerja bagus dengan sengaja akan menyampaikan sinyal pada pasar. Pengumuman yang dilakukan oleh perusahaan tentu akan mempengaruhi reaksi investor yang akan berakibat kepada naik turunnya harga saham perusahaan.Teori sinyal akan membantu perusahaan selaku agen, pemilik, dan pihak luar atau pihak ketiga perusahaan untuk mengurangi asimetris informasi dengan menghasilkan informasi kinerja keuangan yang berkualitas dan terintegrasi (Nariman, 2016).

\section{Laporan Keuangan}

Laporan keuangan adalah suatu informasi penting bagi para pemakai laporan keuangan yang digunakan dalam pengambilan keputusan ekonomi. Hasil analisis memberi gambaran tentang kecenderungan dan hubungan yang dijadikan penilaian terhadap kesuksesan suatu perusahaan dimasa yang akan datang (Effendi et al, 2016). 


\section{Analisis Rasio Keuangan}

Menurut Murhadi (2015:56) menyatakan bahwa "analisis rasio digunakan dengan cara membandingkan suatu angka tertentu pada suatu akun terhadap angka dari akun lainnya.

\section{Kebangkrutan}

Menurut Hanafi (2014: 638) dalam (Wulandari et al, 2017) yang menyatakan perusahaan dapat dikatakan bangkrut apabila perusahaan itu mengalami kesulitan yang kecil yaitu masalah likuiditas, dan sampai kesulitan yang berat yaitu solvabel (utang lebih besar dibandingkan dengan aset).

\section{Analisis Model Zmijewski (X-Score)}

Perluasan studi dalam prediksi kebangkrutan dilakukan oleh Zmijewski (1984) yang menambah dasar rasio keuangan sebagai deteksi alat untuk kegagalan keuangan perusahaan. Model yang berhasil dikembangkan adalah:

\section{$X=-4,3-4,5 \times 1+5,7 \times 2-0,004 \times 3$}

Rasio keuangan yang dianalisis adalah rasio keuangan yang terkandung dalam model Zmijewski,yaitu:

$\mathrm{X} 1$ = Return on Asset (Laba setelah pajak/ Total aset)

$\mathrm{X} 2$ = Debt Ratio $($ Total liabilitas/Total aset)

X3 = Current Ratio (Aset lancar/ liabilitas lancar)

Zmijewski (1984) menyatakan bahwa suatu perusahaan dianggap tertekan jika perusahaannya probabilitasnya lebih besar dari 0. Dengan kata lain, nilai X-nya adalah 0. Oleh karena itu, nilai cutt-off yang berlaku dalam model ini adalah 0. Ini berarti perusahaan dengan nilai $\mathrm{X}$ lebih besar dari atau sama dengan 0 diperkirakan mengalami kebangkrutan dimasa depan. Sebaliknya, perusahaan dengan nilai X-nya lebih dari kecil 0 diperkirakan tidak mengalami kebangkrutan (Primasari, 2017).

\section{Analisis Model Springate (S-Score)}

Model satu ini adalah model kebangkrutan yang dikembangkan oleh Gorgon LV Springate pada tahun 1978. Model Springate adalah model yang menggunakan rasio berganda analisis diskriminan (MDA). Dalam metode MDA dibutuhkan lebih banyak dari satu rasio keuangaan terkait dengan kebangkrutan perusahaan untuk membangun model yang baik. Untuk menentukan rasio dimanapun itu dapat mendeteksi kemungkinan MDA untuk pilih 4 rasio dari 19 rasio keuangan yang populer di literatur, yang mampu membedakan antara bisnis yang tidak bangkrut dan bangkrut. Model Springate adalah :

$S=1,03 \mathrm{~A}+3,07 \mathrm{~B}+0,66 \mathrm{C}+0,4 \mathrm{D}$ 
Keterangan:

A = Modal Kerja/ Total Aset

B = Laba Sebelum Bunga dan Pajak/ Total Aset

$\mathrm{C}=$ Laba Sebelum Pajak/ Liabilitas Lancar

$\mathrm{D}=$ Penjualan / Total Aset

Model Springate ini memiliki perhitungan standar dimana perusahaan memiliki nilai $\mathrm{S}>0,862$ yang tergolong perusahaan sehat, sedangkan perusahaan dengan nilai $\mathrm{S}<0,862$ diklasifikasikan sebagai potensial perusahaan bangkrut (Sinarti \& Sembiring, 2015).

\section{Harga Saham}

Menurut Sunyoto (2013: 119) menyatakan saham adalah alat bukti kepemilikan atas aset perusahaan yang menerbitkan saham, meliputi saham biasa, dan saham preferen. Harga saham adalah penentuan perdagangan di pasar modal yang dipengaruhi oleh permintaan dan penawaran dari banyak entitas yang berkepentingan di dalamnya seperti perusahaan maupun pemegang saham (Adriawan \& Saelan, 2016).

\section{Kerangka Konseptual}

Secara sistematis kerangka konseptual pada penelitian ini dapat digambarkan sebagai berikut:

\section{Gambar 2.1 Kerangka Konseptual.}

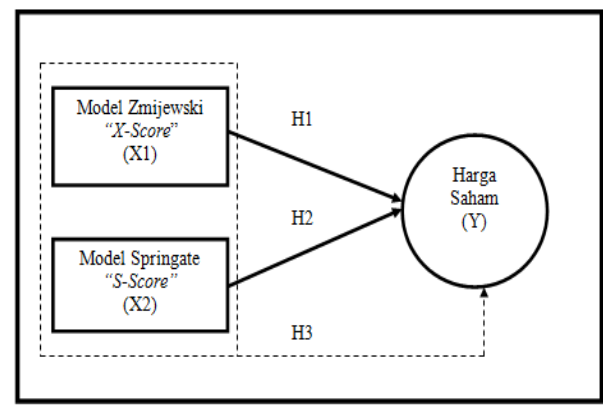

\section{Keterangan:}

$\longrightarrow$ : Pengaruh secara parsial variabel $\mathrm{X}$ terhadap $\mathrm{Y}$

: Pengaruh secara simultan variabel $\mathrm{X}$ terhadap $\mathrm{Y}$

\section{Hipotesis}

Hipotesis dalam penelitian ini dikembangkan dari telaah hasil penelitian sebelumnya sebagai jawaban sementara dari masalah atau pertanyaan penelitian yang memerlukan pengujian secara empiris.

\section{Pengaruh Kebangkrutan Model Zmijewski (X-Score) Terhadap Harga Saham Pada}

\section{Perusahaan}

Hubungan model zmijewski ( $x$-score) terhadap harga saham dapat dijelaskan dalam penelitian (Wibowo, 2015) yang mengatakan "Terdapat hubungan antara model 
kebangkrutan zmijewski dengan harga saham. Berbeda dengan penelitian yang diteliti oleh (Indrabudiman, 2017) yang mengatakan bahwa tidak ada hubungan yang kuat antara model kebangkrutan zmijewski pada harga saham. Berdasarkan uraian tersebut diatas dapat dirumuskan hipotesis pertama sebagai berikut:

H1:Pengaruh kebangkrutan model zmijewski ( $x$-score) terhadap harga saham pada perusahaan.

\section{Pengaruh Kebangkrutan Model Springate (S-Score) Terhadap Harga Saham Pada} Perusahaan.

Hubungan model springate (s-score) terhadap harga saham dapat dijelaskan dalam penelitian (Effendi et al., 2016) yang menyatakan model Spingate berpengaruh signifikan terhadap harga saham. Selanjutnya penelitian yang diteliti oleh (Yuwono, 2016) menunjukkan hasil bahwa model springte berpengaruh terhadap harga saham. Berdasarkan uraian tersebut diatas dapat dirumuskan hipotesis kedua sebagai berikut:

H2: Pengaruh kebangkrutan model springate (s-score) terhadap harga saham pada perusahaan.

\section{Pengaruh Kebangkrutan Model Zmijewski (X-Score) dan Springate (S-Score)}

\section{Terhadap Harga Saham Pada Perusahaan}

Hubungan model zmijewski ( $x$-score) dan springate (s-score) terhadap harga saham dapat dijelaskan dalam penelitiaan yang dilakukan oleh (Syamni, el al, 2018) hasil penelitiannya menemukan bukti bahwa model kebangkrutan yang digunakan secara simultan berpengaruh terhadap harga saham.

Berbeda dengan penelitian yang telah dikemukakan sebelumnya (Abadi \& Ghoniyah, 2016) berpendapat bahwa variabel independen yaitu model Altman, Springate, dan Zmijewski secara simultan tidak berpengaruh terhadap harga saham perusahaan. Berdasarkan Uraian tersebut diatas dapat dirumuskan hipotesis ketiga sebagai berikut:

H3: Pengaruh kebangkrutan model zmijewski ( $x$-score) dan springate (s-score) terhadap harga saham pada perusahaan.

\section{METODE PENELITIAN}

\section{Pendekatan Penelitian}

Penelitian ini menggunakan pendekatan kuantitatif. Menurut metode kuantitatif menurut Sunyoto (2013: 21) menyatakan metode kuantitatif adalah data berupa bilangan atau angka pasti yang bisa digabungkan dan lebih mudah difahami. Dengan melihat pada jumlah masing-masing angka seorang peneliti dapat membuat persepsi. 


\section{Populasi, Sampel, dan Teknik Pengambilan Sampel}

Dalam penelitian ini seluruh populasi menjadi subjek yang akan diteliti. Adapun populasi yang akan diteliti yaitu perusahaan-perusahaan sub sektor pertambangan minyak dan gas bumi dan batubara yang tercatat di BEI tahun 2016-2018. Berdasarkan kriteria yang sudah ditentukan maka sampel yang akan digunakan pada penelitian ini adalah sebanyak 15 perusahaan sub sektor pertambangan minyak dan gas bumi tahun 2016-2018. Dalam penelitian ini teknik sampling yang digunakan adalah purposive sampling. Menurut Sugiyono (2012:85) purposive sampling adalah teknik penentuan sampel dengan pertimbangan tertentu.

\section{Tabel 3.1 Kriteria Pengambilan Sampel Penelitian}

\begin{tabular}{lc}
\hline \multicolumn{1}{c}{ Kriteria } & Total \\
\hline Perusahaan sub sektor pertambangan minyak dan gas bumi dan batubara yang & 29 \\
tercatat di BEI tahun 2016-2018. & $(3)$ \\
Data keuangan perusahaan minyak dan gas bumi yang diolah peneliti tidak & \\
memenuhi uji yang telah ditentukan & $(11)$ \\
Perusahaan batubara yang tidak menerbitkan dan tidak mempunyai kelengkapan \\
data laporan keuangan 2016-2018 yang dibutuhkan dalam penelitian. \\
Jumlah sampel
\end{tabular}

Sumber: Diolah peneliti (2019)

Perusahaan yang bergerak pada sub sektor pertambangan minyak dan gas bumi dan batubara yang tercatat di BEI tahun 2016-2018 hingga saat ini berjumlah 29 perusahaan, namun menurut klasifikasi diatas sampel yang akan digunakan hanya ada 15 perusahaan kriteria adalah sebagai berikut:

Tabel 3.2 Data Sampel Perusahaan Sub Sektor Pertambangan Minyak Dan Gas Bumi

\section{Dan Batubara Pada Tahun 2016-2018}

\begin{tabular}{ccl}
\hline No. & Kode Saham & \multicolumn{1}{c}{ Nama Emiten } \\
\hline 1 & ELSA & Elnusa Tbk \\
2 & ESSA & Surya Esa Perkasa Tbk \\
3 & MEDC & Medco Energi Internasional Tbk \\
4 & RUIS & Radiant Utama Interinsco Tbk \\
5 & ADRO & Adaro Energy Tbk \\
6 & ARII & Atlas Resources Tbk \\
7 & BSSR & Baramulti Suksessarana Tbk \\
8 & BYAN & Bayan Resources Tbk \\
9 & SMMT & Golden Eagle Energy Tbk \\
10 & GEMS & Golden Energy Mines Tbk \\
11 & ITMG & Indo Tambangraya Megah Tbk \\
12 & MBAP & Mitrabara Adiperdana Tbk \\
13 & PTBA & Tambang Batubara Bukit Asam Tbk \\
14 & PTRO & Petrosea Tbk \\
15 & TOBA & Toba Bara Sejahtera Tbk \\
\hline Sula
\end{tabular}

Sumber: Diolah peneliti (2019) 


\section{Variabel Penelitian}

Dalam penelitian ini terdapat dua variabel yang digunakan, yaitu: variabel independen dan variabel dependen. Dalam penelitian ini variabel dependennya adalah harga saham. Sedangkan variabel independenya adalah model zmijewski ( $X$-Score) dan model springate $(S$ Score).

\section{Metode Pengumpulan Data}

Ada dua cara metode pengumpulan yang digunakan, adalah sebagai beikut:

\section{Studi Kepustakaan}

Menurut Rukajat (2018:27) Studi kepustakaan yaitu teknik pengumpulan data dengan jalan mempelajari bahan-bahan bacaan yang berupa, catatan-catatan kuliah, buku-buku, literatur serta peraturan-peraturan yang ada kaitannya dengan masalah penelitian.

\section{Dokumentasi}

Dalam Penelitian ini, peneliti mengumpulkan data tahunan periode 2016-2018 melalui laporan keuangan perusahaan sub sektor pertambangan minyak dan gas bumi dan batubara yang dipublikasikan di Bursa Efek Indonesia.

\section{Definisi Operasional}

Variabel-variabel yang digunakan adalah sebagai berikut:

\section{Variabel Independen}

Pada penelitian ini variabel independen yang digunakan adalah sebagai berikut:

a. Model Zmijewski (X-Score) sebagai (X1).

Perluasan studi dalam prediksi kebangkrutan dilakukan oleh Zmijewski (1984) yang menambah dasar rasio keuangan sebagai deteksi alat untuk kegagalan keuangan perusahaan. Model yang berhasil dikembangkan adalah:

\section{$X=-4,3-4,5 \times 1+5,7 \times 2-0,004 \times 3$}

Rasio keuangan yang dianalisis adalah rasio keuangan yang terkandung dalammodel Zmijewski,yaitu:

$\mathrm{X} 1$ = Return on Asset (Laba setelah pajak/ Total aset)

$\mathrm{X} 2=$ Debt Ratio $($ Total liabilitas/Total aset $)$

$\mathrm{X} 3=$ Current Ratio(Aset lancar/ liabilitas lancar)

Zmijewski (1984) menyatakan bahwa suatu perusahaan dianggap tertekan jika perusahaannya probabilitasnya lebih besar dari 0. Dengan kata lain, nilai X-nya adalah 0. Oleh karena itu, nilai cutt-off yang berlaku dalam model ini adalah 0. Ini berarti perusahaan dengan nilai $\mathrm{X}$ lebih besar dari atau sama dengan 0 diperkirakan mengalami kebangkrutan 
dimasa depan. Sebaliknya, perusahaan dengan nilai X-nya lebih kecil dari 0 diperkirakan tidak mengalami kebangkrutan (Primasari, 2017).

b. Model Springate (S-Score) sebagai (X2).

Model satu ini adalah model kebangkrutan yang dikembangkan oleh Gorgon LV Springate pada tahun 1978. Model Springate adalah model yang menggunakan rasio berganda analisis diskriminan (MDA). Dalam metode MDA dibutuhkan lebih banyak dari satu rasio keuangaan terkait dengan kebangkrutan perusahaan untuk membangun model yang baik. Untuk menentukan rasio dimanapun itu dapat mendeteksi kemungkinan MDA untuk pilih 4 rasio dari 19 rasio keuangan yang populer di literatur, yang mampu membedakan antara bisnis yang tidak bangkrut dan bangkrut. Model Springate adalah :

$S=1,03 A+3,07 \mathrm{~B}+0,66 \mathrm{C}+0,4 \mathrm{D}$

Keterangan:

A = Modal Kerja/ Total Aset

B = Laba Sebelum Bunga dan Pajak/ Total Aset

$\mathrm{C}=$ Laba Sebelum Pajak/ Liabilitas Lancar

$\mathrm{D}=$ Penjualan / Total Aset

Model Springate ini memiliki perhitungan standar dimana perusahaan memiliki nilai $S>0,862$ yang tergolong perusahaan sehat, sedangkan perusahaan dengan nilai $S<0,862$ diklasifikasikan sebagai potensial perusahaan bangkrut (Sinarti \& Sembiring, 2015).

\section{Variabel Dependen}

Diketahui variabel dependen pada penelitian ini yaitu Harga Saham (Y). Dan harga penutupan (Closing Price) yang akan diterapkan dalam penelitian. Harga penutupan adalah harga saham ketika pasar atau bursa efek ditutup pada periode tertentu (Marcelina \& Yuliandhari, 2014).

\section{Metode Analisis Data}

Analisis data yang digunakan pada penelitian ini adalah sebagai berikut:

\section{Analisis Kebangkrutan}

Adapun model kebangkrutan yang digunakan dalam analisis kebangkrutan adalah sebagai berikut:

1. Model Zmijewski (X-Score)

2. Model Springate (S-Score)

\section{Uji Statistik Deskriptif}

\section{Uji Asumsi Klasik}

\section{Uji Analisis Regresi Linear Berganda}


Menurut Augustine dan Kristaung (2013:150-151) berpendapat regresi linier berganda merupakan pengembangan dari analisis regresi sederhana. Kegunaannya adalah untuk meramalkan nilai variabel terikat (Y) apabila variabel bebasnya (X) dua atau lebih. Analisis regresi berganda bertujuan untuk membuktikan ada tidaknya hubungan fungsional atau hubungn kausal antara dua atau lebih variabel bebas $\mathrm{X} 1, \mathrm{X} 2, \ldots, \mathrm{Xn}$ terhadap suatu variabel terikat Y. Persamaan regresi berganda dirumuskan sebagai berikut:

$Y=a+b 1 X 1+b 2 X 2+e$

Dimana :

$\mathrm{Y}=$ Harga Saham

$\alpha=$ Nilai Konstanta

b1, b2 = Koefisien Regresi

X1 = Nilai Rasio Keuangan Zmijewski

X2 = Nilai Rasio Keuangan Springate

e $=$ error atau sisa (residual)

\section{Uji Hipotesis}

\section{Uji t (parsial)}

Menurut Chandrarin (2017:141) Uji t bertujuan untuk menguji signifikansi pengaruh masing-masing variabel bebas terhadap variabel terikat yang diformulasikan dalam model.

\section{Uji F (Simultan)}

Menurut Chandrarin (2017:140) Uji F dilakukan dengan tujuan untuk menguji apakah pengaruh semua variabel independen terhadap satu variabel dependen sebagaimana yang diformulasikan dalam suatu model persamaan regresi linier berganda sudah tepat (fit).

\section{Koefesien Determinasi $\left(\mathbf{R}^{2}\right)$}

Koefesien determinasi dengan simbol $r^{2}$ menurut Augustine dan Kristaung (2013:134) merupakan proporsi variabilitas dalam satu data yang terhitung berdasarkan pada model statistik. Dengan kata lain, $\mathrm{r}^{2}$ merupakan rasio varibilitas nilai-nilai yang dibuat model dengan variabilitas nilai data asli. Secara umum, $\mathrm{r}^{2}$ digunakan sebagai informasi mengenai kecocokan suat model. Dalam regresi, $\mathrm{r}^{2}$ ini dijadikan sebagai pengukuran seberapa baik garis regresi mendekati nilai data asli yang dibuat model. Jika $\mathrm{r}^{2}$ sama dengan 1 maka angka tersebut menunjukkan garis regresi cocok dengan data secara sempurna. 


\section{HASIL \& PEMBAHASAN}

\section{Hasil Penelitian}

\section{Analisis Kebangkrutan}

\section{Hasil perhitungan Model Zmijewski ( $X$-Score)}

Berdasarkan perhitungan analisis prediksi kebangkrutan Zmijewski (X-Score) diperolah hasil seperti dalam Tabel 4.1 sebagai berikut:

Tabel 4.1 Prediksi kebangkrutan Perusahaan Pertambangan Minyak dan Gas Bumi dan Batubara yang Tercatat di BEI Tahun 2016-2018 Model Zmijewski

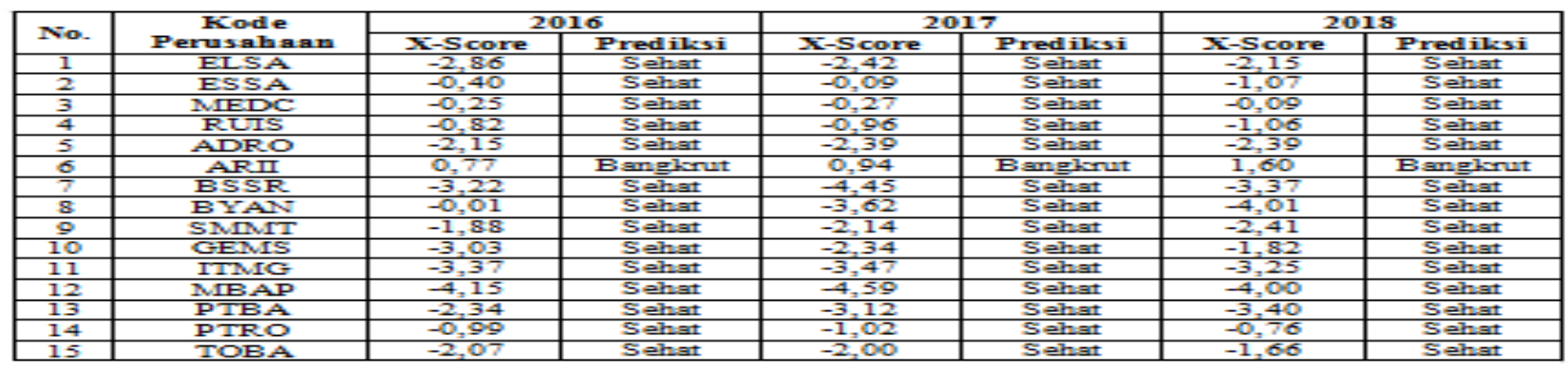

Sumber: Data sekunder diolah peneliti (2019)

Analisis terhadap perusahaan pertambangan minyak dan gas bumi dan batubara dengan menggunakan model Zmijewski pada tahun 2016, 2017, dan 2018 menunjukkan hasil yang sama, yaitu 93,3\% atau 14 perusahaan kategori sehat. Sedangkan yang masuk kategori perusahaan yang bangkrut menunjukkan hasil 6,7\% atau 1 perusahaan.

\section{Hasil perhitungan Model Springate (S-Score)}

Berdasarkan perhitungan analisis prediksi kebangkrutan Springate (S-Score) diperolah hasil seperti dalam Tabel 4.2 sebagai berikut:

Tabel 4.2 Prediksi kebangkrutan Perusahaan Pertambangan Minyak dan Gas Bumi dan Batubara yang Tercatat di BEI Tahun 2016-2018 Model Springate

\begin{tabular}{|c|c|c|c|c|c|c|c|}
\hline \multirow{2}{*}{ No. } & \multirow{2}{*}{$\begin{array}{c}\text { Kode } \\
\text { Perusahaan }\end{array}$} & \multicolumn{2}{|c|}{2016} & \multicolumn{2}{|c|}{2017} & \multicolumn{2}{|c|}{2018} \\
\hline & & S-Score & Prediksi & S-Score & Predilksi & S-Score & Predilksi \\
\hline 1 & ELSA & 1,17 & Sehat & 1,03 & Sehat & 1,12 & Sehat \\
\hline 2 & ESSA & 0,18 & Banglarut & 0,05 & Banglsnut & 0,46 & Banglenut \\
\hline 3 & MEDC & 0,56 & Banglarut & 0,61 & Banglerut & 0,72 & Banglenut \\
\hline 4 & RUIS & 0,87 & Sehat & 0,78 & Banglenut & 0,91 & Sehat \\
\hline 5 & ADRO & 1,14 & Sehat & 1,60 & Sehat & 1,37 & Sehat \\
\hline 6 & ARII & $-0,66$ & Banglanut & $-0,44$ & Banglsnut & $-0,54$ & Banglerut \\
\hline 7 & BSSR & 1,65 & Sehat & 3,85 & Sehat & 2,78 & Sehat \\
\hline 8 & BYAN & 1,44 & Sehat & 3,32 & Sehat & 4,08 & Sehat \\
\hline 9 & SMDMT & $-0,08$ & Banglanut & 0,51 & Banglenut & 0,80 & Banglerut \\
\hline 10 & GEMS & 2,54 & Sehat & 2,89 & Sehat & 2,65 & Sehat \\
\hline 11 & ITMG & 2,08 & Sehat & 2,73 & Sehat & 2,69 & Sehat \\
\hline 12 & MIBAP & 3,15 & Sehat & 4,13 & Sehat & 3,28 & Sehat \\
\hline 13 & PTBA & 1,26 & Sehat & 2,38 & Sehat & 2,35 & Sehat \\
\hline 14 & PTRO & 0,61 & Banglanut & 0,75 & Banglerut & 1,08 & Sehat \\
\hline 15 & TOBA & 0,97 & Sehat & 1,63 & Sehat & 1,58 & Sehat \\
\hline
\end{tabular}


Sumber: Data sekunder diolah peneliti (2019)

Analisis terhadap perusahaan pertambangan minyak dan gas bumi dan batubara dengan model Springate pada tahun 2016 menunjukkan 66,7\% atau 10 perusahaan kategori sehat, pada tahun 2017 menunjukkan $60 \%$ atau 9 perusahaan kategori sehat, sedangkan pada tahun 2018 menunjukkan hasil 73,3\% atau 11 perusahaan yang termasuk kategori sehat. Sedangkan yang termasuk perusahaan bangkrut pada tahun 2016 menunjukk 33,3\% atau 5 perusahaan dan pada tahun 2017 yang termasuk kategori bangkrut menunjukkan hasil 40\% atau 6 perusahaan. Sedangkan pada tahun 2018 menunjukkan hasil 26,7\% atau 4 perusahaan yang termasuk kategori berpotensi bangkrut.

Tabel 4.3 Perbandingan Prediksi kebangkrutan Perusahaan Pertambangan Minyak dan Gas Bumi dan Batubara yang Tercatat di BEI Tahun 2016-2018 Model Zmijewski dan

\section{Model Springate}

\begin{tabular}{|c|c|c|c|c|c|c|c|}
\hline \multirow{2}{*}{ No. } & \multirow{2}{*}{$\begin{array}{c}\text { Kode } \\
\text { Perusahaan }\end{array}$} & \multicolumn{2}{|c|}{2016} & \multicolumn{2}{|c|}{2017} & \multicolumn{2}{|c|}{2018} \\
\hline & & X-Score & S-Score & $X-$ Score & S-Score & $x-$ Score & S-Score \\
\hline 2 & ESSA & Sehat & Banglerut & Sehat & Banglarut & Sehat & Banglarut \\
\hline 4 & RUIS & Sehat & Sehat & Sehat & Banglurut & Sehat & Sehat \\
\hline 5 & ADRO & Sehat & Sehat & Sehat & Sehat & Sehat & Sehat \\
\hline 6 & ARII & Banglerut & Banglerut & Banglerut & Banglorut & Banginut & Banglonut \\
\hline 9 & SMIMT & Sehat & Banglerut & Sehat & Banglorut & Sehat & Banglerut \\
\hline 10 & GEMIS & Sehat & Sehat & Sehat & Sehat & Sehat & Sehat \\
\hline 11 & ITMIG & Sehat & Sehat & Sehat & Sehat & Sehat & Sehat \\
\hline 12 & MBAP & Sehat & Sehat & Sehat & Sehat & Sehat & Sehat \\
\hline 13 & PTBA & Sehat & Sehat & Sehat & Sehat & Sehat & Sehat \\
\hline 14 & PTRO & Sehat & Banglerut & Sehat & Banglerut & Sehat & Sehat \\
\hline
\end{tabular}

Sumber: Data sekunder diolah peneliti (2019)

Perbedaan-perbedaan yang terjadi dapat disebabkan karena hal-hal berikut:

1. Perbedaan dalam menggunakan rumus yang digunakan pada model Zmijewski dan model Springate. Model Zmijewski menggunakan rumus $X$-Score $=-4,3-4,5 X 1+5,7 X 2-0,004 X 3$ dengan kriteria jika $X<0=$ tergolong perusahaan sehat dan jika $X>0=$ tergolong perusahaan bangkrut. Sedangkan model Springate menggunakan rumus $S$-Score $=1,03 \mathrm{~A}+3,07 \mathrm{~B}+$ $0,66 \mathrm{C}+0,4 \mathrm{D}$ dengan kriteria $\mathrm{S}>0,862=$ tergolong perusahaan sehat dan jika $\mathrm{S}<0,862=$ tergolong perusahaan bangkrut.

2. Terjadi perubahan biaya yang cukup signifikan mulai dari tahun 2016 sampai tahun 2018 sehingga cukup mempengaruhi hasil perhitungan model Zmijewski dan model Springate.

3. Periode tahunan yang digunakan jangkanya relatif pendek yaitu 3 tahun, sehingga tidak bisa mengetahui perubahan-prerubahan secara lebih rinci. 


\section{Statistik Deskriptif}

Berikut ini merupakan data sampel yang digunakan dalam uji deskriptif :

\section{Model Zmijewski}

Tabel 4.4 Data X1 (Model Zmijewski) 2016-2018

\begin{tabular}{|c|c|c|c|c|}
\hline \multirow{2}{*}{ No. } & \multirow{2}{*}{ Kade } & $\mathbf{2 0 1 6}$ & $\mathbf{2 0 1 7}$ & $\mathbf{2 0 1 8}$ \\
\cline { 3 - 5 } & Sabam & $\mathbf{X}-$-Score & X-Score & X-Score \\
\hline 1 & ELSA & $-2,86$ & $-2,42$ & $-2,15$ \\
\hline 2 & ESSA & $-0,40$ & $-0,09$ & $-1,07$ \\
\hline 3 & MEDC & $-0,25$ & $-0,27$ & $-0,09$ \\
\hline 4 & RUIS & $-0,82$ & $-0,96$ & $-1,06$ \\
\hline 5 & ADRO & $-2,15$ & $-2,39$ & $-2,39$ \\
\hline 6 & ARI & 0,77 & 0,94 & 1,60 \\
\hline 7 & BSSR & $-3,22$ & $-4,45$ & $-3,37$ \\
\hline 8 & BYAN & $-0,01$ & $-3,62$ & $-4,01$ \\
\hline 9 & SMIMT & $-1,88$ & $-2,14$ & $-2,41$ \\
\hline 10 & GEMS & $-3,03$ & $-2,34$ & $-1,82$ \\
\hline 11 & ITMG & $-3,37$ & $-3,47$ & $-3,25$ \\
\hline 12 & MBAP & $-4,15$ & $-4,59$ & $-4,00$ \\
\hline 13 & PTBA & $-2,34$ & $-3,12$ & $-3,40$ \\
\hline 14 & PTRO & $-0,99$ & $-1,02$ & $-0,76$ \\
\hline 15 & TOBA & $-2,07$ & $-2,00$ & $-1,66$ \\
\hline
\end{tabular}

Sumber: Data sekunder diolah peneliti (2019)

\section{Model Springate}

Tabel 4.5 Data X2 (Model Springate) 2016-2018

\begin{tabular}{|c|c|c|c|c|}
\hline \multirow{2}{*}{ No. } & \multirow{2}{*}{$\begin{array}{c}\text { Kode } \\
\text { Saham }\end{array}$} & $\mathbf{2 0 1 6}$ & $\mathbf{2 0 1 7}$ & $\mathbf{2 0 1 8}$ \\
\cline { 3 - 5 } & & S-Score & S-Score & S-Score \\
\hline 1 & ELSA & 1,17 & 1,03 & 1,12 \\
\hline 2 & ESSA & 0,18 & 0,05 & 0,46 \\
\hline 3 & MEDC & 0,56 & 0,61 & 0,72 \\
\hline 4 & RUIS & 0,87 & 0,78 & 0,91 \\
\hline 5 & ADRO & 1,14 & 1,60 & 1,37 \\
\hline 6 & ARI & $-0,66$ & $-0,44$ & $-0,54$ \\
\hline 7 & BSSR & 1,65 & 3,85 & 2,78 \\
\hline 8 & BYAN & 1,44 & 3,32 & 4,08 \\
\hline 9 & SMMT & $-0,08$ & 0,51 & 0,80 \\
\hline 10 & GEMS & 2,54 & 2,89 & 2,65 \\
\hline 11 & ITMG & 2,08 & 2,73 & 2,69 \\
\hline 12 & MBAP & 3,15 & 4,13 & 3,28 \\
\hline 13 & PTBA & 1,26 & 2,38 & 2,35 \\
\hline 14 & PTRO & 0,61 & 0,75 & 1,08 \\
\hline 15 & TOBA & 0,97 & 1,63 & 1,58 \\
\hline
\end{tabular}

Sumber: Data sekunder diolah peneliti (2019) 


\section{Harga Saham}

Tabel 4.6 Data Y (Harga Saham) 2016-2018

\begin{tabular}{|c|c|r|r|r|}
\hline \multirow{2}{*}{ No. } & \multirow{2}{*}{$\begin{array}{c}\text { Kode } \\
\text { Saham }\end{array}$} & \multicolumn{1}{|c|}{2016} & \multicolumn{1}{c|}{2017} & \multicolumn{1}{c|}{2018} \\
\cline { 3 - 5 } & & $\begin{array}{c}\text { Harga } \\
\text { Saham }\end{array}$ & $\begin{array}{c}\text { Harga } \\
\text { Saham }\end{array}$ & $\begin{array}{c}\text { Harga } \\
\text { Saham }\end{array}$ \\
\hline 1 & ELSA & 420,00 & 372,00 & 344,00 \\
\hline 2 & ESSA & 220,00 & 220,00 & 322,00 \\
\hline 3 & MEDC & $1.320,00$ & $1.320,00$ & 685,00 \\
\hline 4 & RUIS & 236,00 & 232,00 & 260,00 \\
\hline 5 & ADRO & $1.695,00$ & $1.860,00$ & $1.215,00$ \\
\hline 6 & ARI & 520,00 & 980,00 & 900,00 \\
\hline 7 & BSSR & $1.410,00$ & $2.100,00$ & $2.340,00$ \\
\hline 8 & BYAN & $6.000,00$ & $10.600,00$ & $19.875,00$ \\
\hline 9 & SMMT & 149,00 & 133,00 & 160,00 \\
\hline 10 & GEMS & $2.700,00$ & $2.750,00$ & $2.550,00$ \\
\hline 11 & ITMG & $16.875,00$ & $20.700,00$ & $20.250,00$ \\
\hline 12 & MBAP & $2.090,00$ & $2.900,00$ & $3.493,00$ \\
\hline 13 & PTBA & $12.500,00$ & $11.200,00$ & $4.300,00$ \\
\hline 14 & PTRO & 720,00 & $1.660,00$ & $1.785,00$ \\
\hline 15 & TOBA & $1.245,00$ & $1.955,00$ & $1.696,00$ \\
\hline
\end{tabular}

Sumber: Data sekunder diolah peneliti (2019)

Dari data-data tersebut kemudian dilakukan uji deskriptif, berikut ini adalah hasil dari uji deskriptif :

\section{Tabel 4.7 Uji Deskriptif}

\begin{tabular}{|l|r|r|r|r|r|}
\hline \multicolumn{7}{|c|}{ Descriptive Statistics } \\
\hline & $\mathrm{N}$ & Minimum & Maximum & \multicolumn{1}{c|}{ Mean } & $\begin{array}{c}\text { Std. } \\
\text { Deviation }\end{array}$ \\
\hline $\begin{array}{l}\text { MODEL } \\
\text { ZMIJEWSKI }\end{array}$ & 45 & $-4,59$ & 1,60 & $-1,9676$ & 1,50657 \\
\hline $\begin{array}{l}\text { MODEL } \\
\text { SPRINGATE }\end{array}$ & 45 & -.66 & 4,13 & 1,5114 & 1,23042 \\
\hline $\begin{array}{l}\text { HARGA } \\
\text { SAHAM }\end{array}$ & 45 & 133,00 & 20700,00 & 3716,8222 & 5706,46691 \\
\hline $\begin{array}{l}\text { ValidN N } \\
\text { (listwise) }\end{array}$ & 45 & & & & \\
\hline
\end{tabular}

Sumber : Data diolah peneliti dengan SPSS versi 22, (2019)

Tabel 4.7 menunjukkan bahwa nilai minimum dihasilkan oleh Model Springate sebesar 4,59 dan nilai maximum diperoleh dari Harga Saham sebesar 20700,00 dengan rata-rata tertinggi dihasilkan oleh Harga saham sebesar 3716,8222 dan rata-rata terendah sebesar -1,9676 yang dihasilkan oleh Model Zmijewski. Untuk variabel Model Springate memperoleh rata-rata sebesar 1,5114 sedangkan standard deviasi sebesar 1,23042. Model Zmijewski memperoleh rata-rata sebesar -1,9676 dan standard deviasi sebesar 1,50657. Harga saham memperoleh ratarata sebesar 3716,8222 dan merupakan rata-rata terbesar dari rata-rata variabel lainnya dengan standard deviasi sebesar 5706,46691.

\section{Uji Asumsi Klasik}

\section{Uji Normalitas}

Plot grafik menjelaskan asumsi normalitas terpenuhi jika titik-titik pada grafik mendekati atau berada di sekitar sumbu diagonalnya. 


\section{Gambar 4.1 Uji Asumsi Klasik Normalitas}

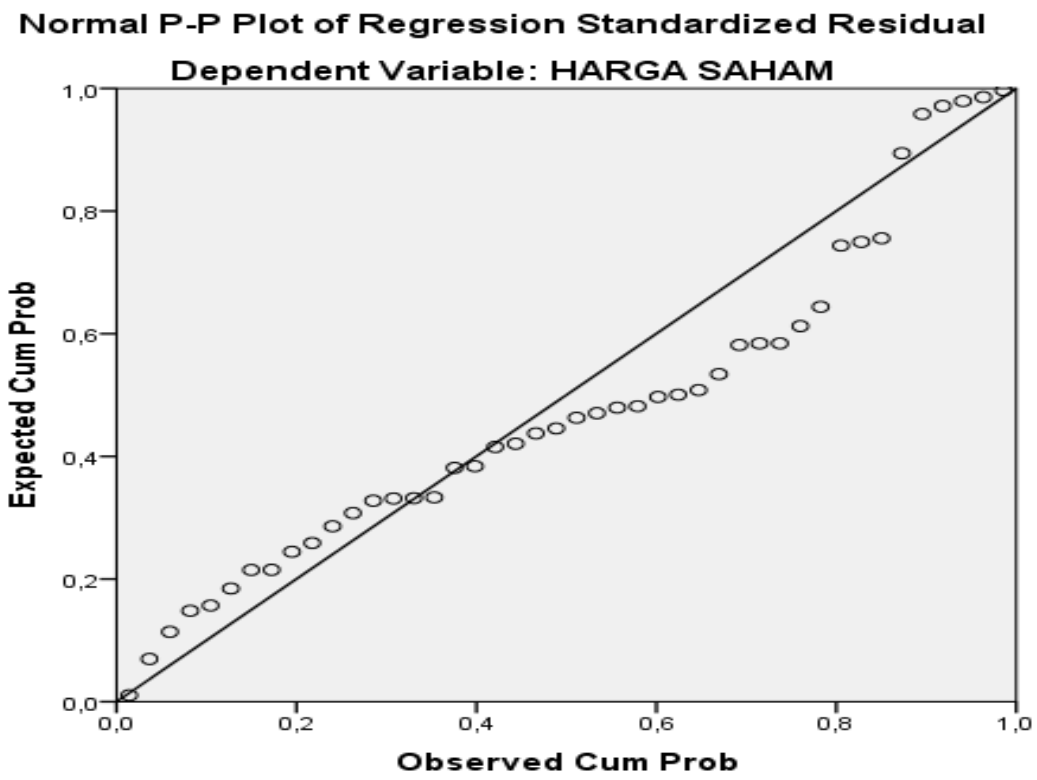

Sumber : Data diolah peneliti dengan SPSS versi 22, (2019)

Gambar 4.1 menunjukkan bahwa data menyebar di sekitar diagram dan mengikuti model regresi sehingga dapat disimpulkan bahwa data yang diolah merupakan data yang terdistribusi normal sehingga uji normalitas terpenuhi.

\section{Uji Multikolinearitas}

Uji multikoleniaritas adalah untuk melihat ada atau tidaknya korelasi yang tinggi antara variabel bebas dan variabel terikat. Pendeteksian dilakukan dengan melihat nilai VIF < 10 dan tolerance $>0,10$ yang berarti tidak terjadi multikoleniaritas.

Tabel 4.8 Uji Multikolinearitas

\begin{tabular}{|c|c|c|c|c|c|}
\hline & & Coef & icient & & \\
\hline & Corr & lations & & Collinearity & tatistics \\
\hline Model & Zero-order & Partial & Part & Tolerance & VIF \\
\hline 1 (Constant) & & & & & \\
\hline $\begin{array}{l}\text { MODEL } \\
\text { ZMIJEWSKI }\end{array}$ &,- 439 & .010 & ,009 & .260 & 3,850 \\
\hline $\begin{array}{l}\text { MODEL } \\
\text { SPRINGATE }\end{array}$ & .516 & 301 & 270 & .260 & 3,850 \\
\hline
\end{tabular}

Sumber : Data diolah peneliti dengan SPSS versi 22, (2019)

Tabel 4.8 menunjukkan variabel Model Zmijewski memiliki nilai tolerance sebesar 0,260 , Model Springate memiliki nilai tolerance sebesar 0,260 , yang semuanya $>0,1$ dan nilai VIF dari Model Zmijewski sebesar 3,850, Model Springate sebesar 3,850, yang seluruhnya < 10. Kesimpulannya adalah tidak terjadi multikolinearitas antar variabel bebas dalam persamaan regresi. 


\section{Uji Heteroskedastisitas}

\section{Gambar 4.2 Uji Asumsi Klasik Heteroskedastisitas}

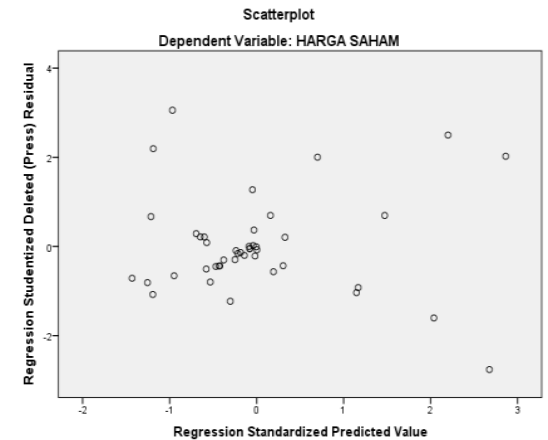

Sumber : Data diolah peneliti dengan SPSS versi 22, (2019)

Hasil pada gambar 2 menunjukkan bahwa scatterplot tidak membentuk pola yang jelas, kemudian titik-titik menyebar diatas titik 0 dan dibawah titik nol, maka dapat disimpulkan bahwa tidak ada heteroskedastisitas.

\section{Uji Autokorelasi}

Uji Autokorelasi menurut Sunyoto (2013:97) merupakan persamaan regresi yang baik adalah yang tidak memiliki masalah autokorelasi, jika terjadi autokorelasi maka persamaan tersebut menjadi tidak baik atau tidak layak dipakai prediksi.

\section{Tabel 4.9 Uji Autokorelasi}

\begin{tabular}{|c|c|c|c|c|c|}
\hline \multicolumn{6}{|c|}{ Model Summary } \\
\hline Model & $\mathrm{R}$ & $\begin{array}{c}\text { R } \\
\text { Square }\end{array}$ & $\begin{array}{l}\text { Adjusted } \\
\text { R Square }\end{array}$ & $\begin{array}{l}\text { Std. Error of } \\
\text { the Estimate }\end{array}$ & $\begin{array}{l}\text { Durbin- } \\
\text { Watson }\end{array}$ \\
\hline 1 & $.516^{2}$ & .266 & .231 & 5003,99542 & 1,641 \\
\hline \multicolumn{6}{|c|}{ 9. Predictors: (Constant), SPRाINGATE, ZMIJEWSK } \\
\hline \multicolumn{6}{|c|}{ b. DependentVariable:HARGA SAHAM } \\
\hline
\end{tabular}

Sumber : Data diolah peneliti dengan SPSS versi 22, (2019)

Berdasarkan tabel 4.9 hasil analisis regresi diperoleh nilai DW sebesar 1,641. Sedangkan nilai dU diperoleh sebesar 1.6148 dan $4-\mathrm{dU}=2,3852$. Dengan demikian bahwa rumus $\mathrm{du}<\mathrm{dw}<4-\mathrm{du}$ diperoleh nilai sebesar $1.6148<1,641<2,3852$. Kesimpulannya bahwa nilai DW berada diantara dU dan 4-dU yang menunjukkan bahwa model regresi tersebut tidak terjadi autokorelasi. 


\section{Analisis Regresi Linier Berganda}

\section{Tabel 4.10 Hasil Analisis Regresi Linier Berganda}

\begin{tabular}{|c|c|c|c|c|c|}
\hline \multicolumn{6}{|c|}{ Coefficients $^{2}$} \\
\hline \multirow[b]{2}{*}{ Model } & \multicolumn{2}{|c|}{$\begin{array}{l}\text { Unstandardized } \\
\text { Coefficients }\end{array}$} & \multirow{2}{*}{\begin{tabular}{|c}
$\begin{array}{c}\text { Standardized } \\
\text { Coefficients }\end{array}$ \\
Beta
\end{tabular}} & \multirow[b]{2}{*}{ ] } & \multirow[b]{2}{*}{ Sig. } \\
\hline & $\mathrm{B}$ & Std. Error & & & \\
\hline \begin{tabular}{|l|l}
1 & $($ Constant $)$ \\
\end{tabular} & 126,540 & 1245,439 & &, 102 & .920 \\
\hline $\begin{array}{l}\text { MODEL } \\
\text { ZMIJEWSKI }\end{array}$ & 65,086 & 982,504 & .017 & .066 & .947 \\
\hline $\begin{array}{l}\text { MODEL } \\
\text { SPRINGATE }\end{array}$ & 2460,199 & 1203,020 & .530 & 2,045 &, 047 \\
\hline
\end{tabular}

Sumber : Data diolah peneliti dengan SPSS versi 22, (2019)

Berdasarkan hasil analisis regresi yang disajikan pada tabel 4.10 maka diperoleh nilai konstanta sebesar 126,540 nilai b1 sebesar 65,086 dan nilai b2 sebesar 2460,199. Berdasarkan hasil tersebut maka dapat dibuat persamaan regresi sebagai berikut:

$$
\begin{gathered}
Y=a+b 1 X_{1}+b 2 X_{2}+e \\
Y=126,540+65,086 X_{1}+2460,199 X_{2}+e
\end{gathered}
$$

1. Nilai konstanta dari persamaan regresi sebesar 126,540 dimana jika variabel Model Zmijewski dan Model Springate bernilai nol maka Harga Saham akan bernilai 126,540.

2. Nilai dari koefisien Model Zmijewski $\left(\mathrm{X}_{1}\right)$ sebesar 65,086, jika Zmijewski meningkat 1 satuan, maka Harga Saham akan mengalami peningkatan sebesar 65,086.

3. Nilai dari koefisien Model Springate $\left(\mathrm{X}_{2}\right)$ sebesar 2460,199 jika Springate meningkat 1 satuan, maka Harga Saham akan mengalami peningkatan sebesar 2460,199.

\section{Uji Hipotesis}

\section{Uji t (Parsial)}

Uji statistik t pada dasarnya menunjukkan seberapa jauh pengaruh satu variabel independen secara individual dalam menerangkan variasi variabel dependen.Uji statistik $\mathrm{t}$ digunakan untuk meguji hipotesis pertama sampai dengan hipotesis keempat. Dari hasil pengujian analisis regresi sebagaimana pada lampiran diketahui nilai t hitung sebagai berikut: 


\section{Tabel 4.11 Uji t}

\begin{tabular}{|c|c|c|c|c|c|}
\hline \multicolumn{6}{|c|}{ Coefficients $^{2}$} \\
\hline \multirow[b]{2}{*}{ Model } & \multicolumn{2}{|c|}{$\begin{array}{c}\text { Unstandardized } \\
\text { Coefficients }\end{array}$} & \multirow{2}{*}{$\begin{array}{c}\text { Standardized } \\
\text { Coefficients } \\
\text { Beta }\end{array}$} & \multirow[b]{2}{*}{$t$} & \multirow[b]{2}{*}{ Sig. } \\
\hline & $\mathrm{B}$ & Std. Error & & & \\
\hline \begin{tabular}{l|l}
1 & $($ Constant $)$ \\
\end{tabular} & 126,540 & 1245,439 & &, 102 & .920 \\
\hline $\begin{array}{l}\text { MODEL } \\
\text { ZMIJEWSKI }\end{array}$ & 65,086 & 982,504 &, 017 &, 066 &, 947 \\
\hline $\begin{array}{l}\text { MODEL } \\
\text { SPRINGATE }\end{array}$ & 2460,199 & 1203,020 & .530 & 2,045 & .047 \\
\hline
\end{tabular}

Sumber : Data diolah peneliti dengan SPSS versi 22, (2019)

Pada Tabel 4.11 menunjukkan hasil estimasi variabel Model Zmijewski sebesar nilai t $=0,066$ Nilai Signifikansi di atas 0,05 yaitu 0,967 hal ini menunjukkan bahwa variabel Model Zmijewski tidak signifikan terhadap Harga saham. Dari hasil estimasi variabel Model Springate diperoleh nili $\mathrm{t}=2,045$ Nilai signifikansi lebih kecil dari 0,05 yaitu 0,047 hal ini menunjukkan bahwa variabel Model Springate memiliki pengaruh positif dan signifikan terhadap Harga saham.

\section{Tabel 4.12 Hasil Uji t}

\begin{tabular}{|c|c|c|c|c|c|}
\hline & t-tabel & $\begin{array}{c}\text { df } \\
(\mathbf{n}-\mathrm{k})\end{array}$ & t-hitung & Sig. & Keterangan \\
\hline Modal Zmijewski & 2,017 & 43 & 0,066 & 0,967 & $\begin{array}{c}\text { Tidak } \\
\text { Signifikan }\end{array}$ \\
\hline Model Springate & 2,017 & 43 & 2,045 & 0,047 & Signifikan \\
\hline
\end{tabular}

Sumber : Data diolah peneliti dengan SPSS versi 22, (2019)

\section{a. Variabel Model Zmijewski ( $\left.\mathbf{X}_{1}\right)$}

Dari hasil Tabel.4.12 menunjukkan nilai t-hitung sebesar 0,066, t-tabel sebesar 2,017. Karena t-hitung 0,066 < t-tabel sebesar 2,017 dan nilai signifikansi 0,967>0,05. Jadi dapat disimpulkan bahwa Model Zmijewski tidak signifikan terhadap Harga Saham, maka $\mathrm{H}_{0}$ diterima dan $\mathrm{H}_{1}$ ditolak.

\section{b. Variabel Model Springate $\left(\mathbf{X}_{2}\right)$}

Dari hasil Tabel 4.12 menunjukkan nilai t- hitung sebesar 2,045, t-tabel sebesar 2,017. Karena t-hitung 2,045>t-tabel 2,028 dan nilai signifikansi 0,047 <0,05. Jadi dapat disimpulkan bahwa Model Springate berpengaruh positif dan signifikan terhadap Harga Saham, maka $\mathrm{H}_{0}$ ditolak dan $\mathrm{H}_{2}$ diterima. 


\section{Uji F (Simultan)}

Uji statistik F pada dasarnya menunjukkan apakah semua variabel dependen yang dimasukkan dalam model memiliki pengaruh secara bersama-sama terhadap variabel independen.

\section{Tabel 4.13 Uji F}

\begin{tabular}{|c|c|c|c|c|c|c|}
\hline \multicolumn{7}{|c|}{ ANOVA $^{\top}$} \\
\hline \multicolumn{2}{|c|}{ Model } & Sum of Squares & $\mathrm{df}^{f}$ & Mean Square & $F$ & Sig. \\
\hline \multirow[t]{3}{*}{1} & Regression & 381126897,529 & 2 & 190563448,764 & 7,610 &, $002^{2}$ \\
\hline & Residual & 1051678747,049 & 42 & 26039970,108 & & \\
\hline & Tota & 1432805644,578 & 44 & & & \\
\hline \multicolumn{7}{|c|}{ a. DependentVariable: HARGASARAM } \\
\hline \multicolumn{7}{|c|}{ b. Predictors: (Constart), SPRRINGATE, ZMIJEWGKT } \\
\hline
\end{tabular}

Sumber : Data diolah peneliti dengan SPSS versi 22, (2019)

F-tabel dengan $\alpha=5 \%$

F-tabel $=$ F a df $(\mathrm{k}-1) ;(\mathrm{n}-1)$

F-tabel $=(0,05 ; 2 ; 43)=3,232$

Berdasarkan Tabel 4.13 uji $\mathrm{F}$ dengan menggunakan $\alpha=5 \%$ diperoleh F-tabel sebesar 3,232 sementara hasil regresi diperoleh F-hitung sebesar 7,610 yang berarti F-hitung 7,610 > F-tabel 3,232 dan nilai Sig. 0,002<0,05. Maka dapat disimpulkan bahwa semua variabel independen yaitu Model Zmijewski, dan Model Springate secara bersama-sama berpengaruh signifikan terhadap variabel dependen yaitu Harga Saham, maka $\mathrm{H}_{0}$ ditolak dan $\mathrm{H}_{3}$ diterima.

\section{Koefisien Determinasi $\left(\mathbf{R}^{2}\right)$}

Kekuatan pengaruh variabel bebas terhadap variasi variabel terikat dapat diketahui dari besarnya nilai koefisien determinasi $\left(\mathrm{R}^{2}\right)$ yang berada antara nol dan satu.

Tabel 4.14 Koefisien Determinasi $\left(\mathbf{R}^{2}\right)$

\begin{tabular}{|c|c|c|c|c|c|}
\hline \multicolumn{6}{|c|}{ Model Summary } \\
\hline Model & $\mathrm{R}$ & $\begin{array}{c}R \\
\text { Square }\end{array}$ & $\begin{array}{l}\text { Adjusted } \\
\text { R Square }\end{array}$ & $\begin{array}{c}\text { Std. Error of } \\
\text { the Estimate }\end{array}$ & $\begin{array}{l}\text { Durbin- } \\
\text { Watson }\end{array}$ \\
\hline 1 & $.516^{ \pm}$ & .266 & .231 & 5003,99542 & 1,641 \\
\hline \multicolumn{6}{|c|}{ a. Predictors: (Constant), SPRINGA'E, ZMIJEWSK' } \\
\hline b. Dep & 10 & ble: & RGASR & & \\
\hline
\end{tabular}

Sumber : Data diolah peneliti dengan SPSS versi 22, (2019)

Pada Tabel 4.13 menunjukkan bahwa koefisien determinasi yang ditunjukkan dari nilai adjusted $R 2$ sebesar 0,231. Hal ini berarti menunjukkan bahwa $23 \%$ variabel dependen yaitu Harga Saham dapat dijelaskan oleh dua variabel independen yaitu Model Zmijewski, 
dan Model Springate. Sedangkan sisanya sebesar 77\% dipengaruhi oleh faktor-faktor lain yang tidak diteliti selain kebangkrutan dengan model zmijewski dan model springate.

\section{Pembahasan}

\section{Pengaruh kebangkrutan model zmijewski ( $x$-score) terhadap harga saham pada perusahaan.}

Berdasarkan hasil pengujian yang dilakukan, dapat dijelaskan bahwa Model Zmijewski tidak signifikan terhadap Harga saham. Karena diketahui dari hasil uji hipotesis parsial (uji t) nilai t-hitung 0,066 < t-tabel 2,017 dan nilai sig 0,967>0,05. Jadi dapat disimpulkan bahwa Model Zmijewski tidak signifikan terhadap Harga Saham, maka $\mathrm{H}_{0}$ diterima dan $\mathrm{H}_{1}$ ditolak. Dimana semakin tinggi Model Zmijewski maka Harga Saham semakin berkurang.

Artinya, jika Harga Saham menurun maka para investor di pasar modal tidak akan tertarik menanamkan modal di perusahaan tersebut karena bisa diprediksi bahwa perusahaan tersebut akan mengalami kepailitan.

Berdasarkan penjelasan diatas tentang pengaruh variabel independen terhadap variabel dependen, maka hasil penelitian ini sejalan dengan hasil penelitian yang dilakukan oleh Indrabudiman (2017). Tetapi terdapat penelitian yang tidak sejalan dengan penelitian ini yaitu penelitian yang dilakukan oleh Wibowo (2015) yang menyatakan terdapat hubungan antara model kebangkrutan zmijewski dengan harga saham.

\section{Pengaruh kebangkrutan model springate (s-score) terhadap harga saham pada perusahaan}

Hipotetis kedua dalam penelitian ini adalah pengaruh kebangkrutan model springate $(S$ score) berpengaruh terhadap harga saham pada perusahaan. Berdasarkan hasil pengujian yang dilakukan, dapat dijelaskan bahwa model springate berpengaruh positif dan signifikan. Karena diketahui dari hasil uji hipotesis parsial (uji t) nilai t-hitung $2,045>$ t-tabel 2,028 dan nilai signifikansi $0,047<0,05$. Pada sisi positif $\mathrm{H}_{0}$ ditolak dan $\mathrm{H}_{2}$ diterima. Model Springate mempunyai hubungan positif terhadap Harga Saham, dimana semakin tinggi Nilai Model Springate maka Harga Saham semakin tinggi.

Artinya, dengan perolehan nilai Model Springate yang tinggi maka akan berpengaruh terhadap Harga saham, sehingga perusahaan tersebut dapat dikatakan baik dan berhasil dalam menjalankan bisnisnya. Oleh karena itu bisa menjadi nilai positif bagi perusahaan agar investor tertarik menanamkan modal di perusahaan tersebut.

Berdasarkan penjelasan diatas tentang pengaruh variabel independen terhadap variabel dependen, hasil dari penelitian ini mendukung penelitian sebelumnya yang dilakukan oleh Efendi, et, al., (2016) yang menyatakan model Spingate berpengaruh signifikan terhadap harga 
saham. Dan penelitian terdahulu yang dilakukan oleh Yuwono, (2016) menemukan bukti empiris bahwa Model Springate mempunyai pengaruh positif terhadap Harga Saham. Hal ini berarti model regresi layak digunakan dalam penelitian (good fit model).

\section{Pengaruh kebangkrutan model zmijewski ( $x$-score) dan springate (s-score) terhadap harga saham pada perusahaan.}

Hipotetis ketiga dalam penelitian ini adalah pengaruh kebangkrutan model Zmijewski ( $S$ score) dan Model Springate (S-score) berpengaruh terhadap harga saham pada perusahaan. Berdasarkan hasil pengujian yang dilakukan, dapat dijelaskan bahwa semua variabel independen yaitu Model Zmijewski, dan Model Springate berpengaruh secara simultan terhadap variabel dependen yaitu Harga Saham. Hal ini dikarenakan dari hasil perhitungan SPSS menyatakan bahwa nilai F-hitung sebesar 7,610 yang berarti F-hitung 7,610 > F-tabel 3,232 dan nilai Sig. 0,002 < 0,05. Maka dapat disimpulkan bahwa semua variabel independen yaitu Model Zmijewski dan Model Springate secara bersama-sama berpengaruh signifikan terhadap variabel dependen yaitu Harga Saham, maka $\mathrm{H}_{0}$ ditolak dan $\mathrm{H}_{3}$ diterima.

Sementara berdasarkan nilai $\mathrm{R}^{2}$ sebagai koefisien determinasi menunjukkan sebesar $23 \%$ berarti bahwa variabel independen Modal Zmijewski, dan Modal Springate mempengaruhi variabel dependen yaitu Harga Saham sebesar 23\%, sedangkan diluar itu Harga Saham dipengaruhi oleh variabel lain yang tidak dimasukkan dalam penelitian ini yaitu sebesar $77 \%$ dipengaruhi oleh faktor-faktor lain yang tidak diteliti selain kebangkrutan dengan model zmijewski dan model springate.

Maka dapat disimpulkan bahwa adanya pengaruh secara signifikan antara variabel Modal Zmijewski, dan Modal Springate terhadap Harga Saham, dengan tingkat signifikansi 0,002 menunjukkan bahwa variabel independen berpengaruh signifikan terhadap variabel dependen secara simultan terbukti, karena tingkat signifikansi 0,002 lebih kecil dari tingkat taraf nyata yang digunakan sebesar 0,05.

Artinya, Kedua model tersebut apabila disimultankan terjadi persamaan pengaruhnya terhadap Harga saham karena mungkin kedua metode tersebut memiliki tujuan yang sama sebagai model prediksi kebangkrutan.

Hasil penelitian ini mendukung penelitian sebelumnya yang dilakukan oleh Syamni, et, al, (2018) menyatakan bahwa hasil penelitiannya menemukan bukti bahwa model kebangkrutan yang digunakan secara simultan berpengaruh terhadap harga saham. Berbeda dengan penelitian yang telah dikemukakan sebelumnya Abadi \& Ghoniyah (2016) berpendapat bahwa variabel independen yaitu model Altman, Springate, dan Zmijewski secara simultan tidak berpengaruh terhadap harga saham. 


\section{SIMPULAN \& SARAN}

\section{Kesimpulan}

Berdasarkan hasil penelitian mengenai analisis prediksi kebangkrutan terhadap harga saham dengan model zmijewski dan springate pada perusahaan sub sektor pertambangan minyak dan gas bumi dan batubara yang tercatat di BEI tahun 2016-2018, maka dapat disimpulkan sebagai berikut:

1. Variabel Modal Zmijewski tidak signifikan terhadap Harga Saham perusahaan sub sektor pertambangan minyak dan gas bumi dan batubara yang tercatat di BEI 2016-2018.

2. Variabel Modal Springate berpengaruh positif dan signifikan terhadap Harga Saham perusahaan sub sektor pertambangan minyak dan gas bumi dan batubara yang tercatat di BEI 2016-2018.

3. Variabel Modal Zmijewski dan Modal Springate secara simultan berpengaruh signifikan terhadap Harga Saham perusahaan sub sektor pertambangan minyak dan gas bumi dan batubara yang tercatat di BEI 2016-2018.

\section{Saran}

Berdasarkan analisis yang telah dilakukan pada perusahaan sub sektor pertambangan minyak dan gas bumi dan batubara yang tercatat di BEI tahun 2016-2018, terdapat beberapa saran yang dapat peneliti sampaikan untuk penelitian yang selanjutnya dengan topik yang sama yaitu:

1. Bagi Investor dan Calon Investor

Diharapkan untuk para investor maupun calon investor untuk melihat nilai kebangkrutan perusahaan go-publik untuk mengambil keputusan, sebelum membeli atau menjual saham. Dan sebaiknya berhati-hati dalam menginvestasikan dana agar tidak mengalami kerugian dimasa depan, harus lebih selektif dalam memilih perusahaan yang memiliki prospek bisnis yang baik untuk berinvestasi.

2. Bagi Peneliti Selanjutnya

Untuk mengetahui dan manganalisis kondisi kebangkrutan perusahaan disarankan pada peneliti selanjutnya, sebaiknya menambah model Altman agar analisis yang dilakukan benar-benar akurat, karena setiap model analisis memiliki kelemahan dan kelebihan. Kemudian menambah tahun penelitian agar hasil penelitian lebih akurat. 
3. Bagi Pengguna Laporan Keuangan

Bagi pengguna laporan keuangan hasil analisis nilai kebangkrutan model Zmijewski dan

Springate dapat dijadikan media informasi dan pertimbangan pengambilan keputusan ekonomis yang digunakan investor untuk menanamkan dananya pada perusahaan.

4. Bagi Perusahaan

Bagi perusahaan hasil analisis dengan model Zmijewski dan model Springate yang menunjukkan perusahaan dalam kategori berpotensi bangkrut, maka hal ini perlu diwaspai oleh manajemen perusahaan agar segara mengambil tindakan yang tepat untuk mencegah terjadinya kebangkrutan.

\section{DAFTAR PUSTAKA}

Abadi, M. T., \& Ghoniyah, N. (2016). Studi Potensi Kebangkrutan pada Perusahaan Industri Properti Yang Go Public Di Bursa Efek Indonesia. Jurnal Riset Bisnis Indonesia, 13(1), 91-100.

Andriawan, nur fadhli, \& Salean, D. (2016). Analisis Metode Altman Z-Score Sebagai Alat Prediksi Kebangkrutan dan Pengaruhnya Terhadap Harga saham Pada Perusahaan Farmasi yang Terdaftar Di Bursa Efek Indonesia. Jurnal Ekonomi Akuntansi, 1(April), 67-82.

Augustine, Y., \& Kristaung, R.(2013). Metodologi Penelitian Bisnis dan Akuntansi. Jakarta: PT. Dian Rakyat.

Chandrarin, Grahita. (2017). Metode Riset Akuntansi Pendekatan Kuantitatif. Jakarta: Salemba Empat.

Effendi, Affandi, A., \& Sidharta, I. (2016). Analisa Pengaruh Rasio Keuangan Model Springate Terhadap Harga Saham Pada Perusahaan Publik Sektor Telekomunikasi. Jurnal Ekonomi, Bisnis \& Entrepreneurship, 10, 1-16.

Hanafi, Mamduh M. 2016. Manajemen Keuangan. Edisi 2. Yogyakarta : BBFE.

Harlen, Y. S., \& Azizah, D. F. (2016). Analisis Penggunaan Model Altman ( Z-Score ) Untuk Memprediksi Potensi Kebangkrutan ( Studi Kasus Pada Perusahaan Sub Sektor Pertambangan Minyak dan Gas Bumi yang Terdaftar di Bursa Efek Indonesia Tahun 20122016 ). Jurnal Administrasi Bisnis (JAB), 66(1), 79-88.

Hikmah. (2018). Pengaruh Rasio Profitabilitas Terhadap Harga Saham Perusahaan Sub Sektor Minyak Dan Gas Bumi Yang Terdaftar Di Bei. Journal of Management \& Business, 2(1), $56-72$.

Indrabudiman, A. (2017). Descriptive Analysis Stock Price with Zmijewski Bankruptcy Model to Total Assets on Stock Prices. IJSRT, 3(6), 337-340. 
Marcelina, T. A., \& Yuliandhari, W. S. (2014). Prediksi Kebangkrutan Menggunakan Metode Z-Score Perusahaan Transportasi Yang Terdaftar Di Bursa Efek Indonesia Tahun 20082012 Bankruptcy Prediction Using Z-Score Methods and Its Influence on Share Prices of Transportation Companies List on the Indonesia. E-Proceeding of Management, 1(3), 291-298.

Marliawati, S., Syamni, G., \& Zulfiar, E. (2016). Analisis Prediksi Kebangkrutan Pada Perusahaan Pertambangan Batubaradi Bursa Efek Indonesia Periode 2013-2015 Sri Marliawati, Ghazali Syamni, dan Edy Zulfiar. J Jurnal Akuntansi Dan Pembangunan, 2(November), 75-101.

Nariman, A. (2016). Analisis Prediksi Kebangkrutan Dan Harga Saham Pada Perusahaan Pertambangan Batu Bara. Jurnal Riset Akuntansi Dan Keuangan, 12(2), 141-155.

Primasari, Niken Safitri. (2017). Analysis altman z-score, grover score, springate and zmijewski as financial distress signaling (empirical study of consumer goods industry in indonesia). Accounting and Management Journal, Vol. 1, No.1.

Rukajat, Ajat. 2018. Pendekatan Penelitian Kuantitatif: Quantitative Research Approach. Yogyakarta: Deepublish.

Sari, M. P., \& Yunita, I. (2019). Analisis Prediksi Kebangkrutan Dan Tingkat Akurasi Model Springate, Zmijewski, Dan Grover Pada Perusahaan Sub Sektor Logam Dan Mineral Lainnya Yang Terdaftar Di Bursa Efek Indonesia Tahun 2012-2016. JIM UPB, 7(1).

Sinarti, \& Sembiring, T. M. (2015). Bankruptcy Prediction Analysis of Manufacturing Companies Listed in Indonesia Stock Exchange. International Journal of Economics and Financial Issues, 5(Special Issue), 354-359.

Sugiyono. 2015. Metode Penelitian Kuantitatif Kualitatif Dan R\&D. Bandung : Alfabeta. Sunyoto, Danang. 2013. Metodologi Penelitian Akuntansi. Bandung: PT Rafika Aditama. Syamni, G., Majid, M. S. A., \& Siregar, W. V. (2018). Bankruptcy Prediction Models and Stock Prices of the Coal Mining Industry in Indonesia. Etikonomi, 17(1), 57-68. https://doi.org/10.15408/etk.v17i1.6559.

Wibowo, I. T. R. I. (2015). Pengaruh Kinerja Keuangan Berdasarkan Teori Kebangkrutan Zmijewski Terhadap Harga Saham Pada Perusahaan Publik Sektor Keramik , Kaca Dan Porselin Di Bursa Efek Indonesia ( BEI ) periode 2010 - 2014. Jurnal Ekonomi Dan Manajemen, 4(2).

Wulandari, F., Burhanudin, B., \& Widayanti, R. (2017). Analisis Prediksi Kebangkrutan Menggunakan Metode Altman (Z-Score) Pada Perusahaan Farmasi (Studi Kasus Pada Perusahaan yang Terdaftar di Bursa Efek Indonesia Tahun 2011 - 2015). Benefit: Jurnal 
Manajemen Dan Bisnis, 2(1), 15. https://doi.org/10.23917/benefit.v2i1.3237.

Yuwono. (2016). Pengaruh Kinerja Keuangan Berdasarkan Teori Kebangrutan Springate Terhadap Harga Saham Yang Tergabung Dalam Jakarta Islamic Indeks Di Bursa Efek Indonesia Periode 2009 - 2013. Jurnal Ekonomika Dan Manajemen, 5(2), 148-162 